\title{
The impact of robotics assisted programming education on academic success, problem solving skills and motivation
}

\author{
Emre Cam $^{\mathrm{a}}{ }^{*}$ (D), Mubin Kiyici ${ }^{\mathrm{b}}$ (D) \\ a Tokat Gaziosmanpasa University, Turkey. \\ ${ }^{\mathrm{b}}$ Sakarya University, Turkey.
}

Suggested citation: Cam, E. \& Kiyici, M. (2022). The impact of robotics assisted programming education on academic success, problem solving skills and motivation. Journal of Educational Technology \& Online Learning, 5(1), 47-65.

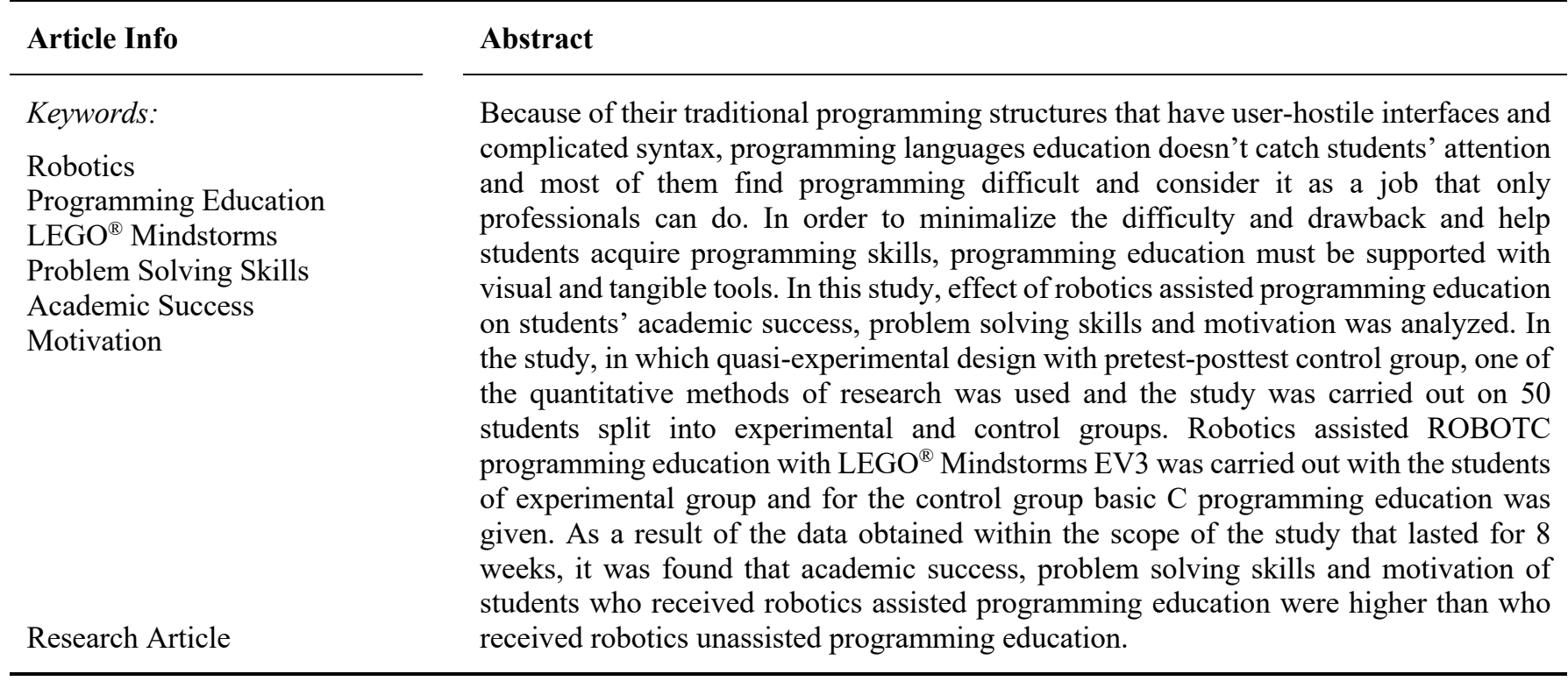

\section{Introduction}

Nowadays, changes occurring in the learning approaches have led to the development and changing of instructional technologies. Along with the constructivist learning approach, learning environments where learners can construct the information themselves have come up. For these brand new learning environments, new and improvable instructional technologies are required. One of these technologies that is used nowadays is Lego which plays a significant role in terms of development of children's metacognitive skills. Learners can design a set of robots and can program them.

Legos are significant for children's development of intelligence (Whitebread et al., 2017). They stand out as substantial and efficient tools as they have the positive effect of developing children's intelligence and individual skills. Legos are colorful modules that are formed by plastic components and also, they can be detached anytime wanted. Space of a block is completed with another block and new structures are formed. Legos offer children interaction with the real world (Resnick et al., 1996). Children using these blocks can construct the objects or structures they see in the real world and while constructing they can find answers

\footnotetext{
* Corresponding author. Department of Computer Technology, Tokat Gaziosmanpasa University, Turkey.

e-mail address: emre.cam@gop.edu.tr

* This research was drived from doctoral dissertation titled the influence of robotic assisted programming education on problem solving skills, academic success and motivation.
}

Doi: http://doi.org/10.31681/jetol.1028825

Received 26 Nov 2021; Revised 10 Jan 2022; Accepted 20 Jan 2022

ISSN: 2618-6586. This is an open Access article under the CC BY license. 
to many questions on their own. Therefore, user participation in robot design processes is considered to make a valuable contribution to the acceptance of social robots in everyday life (Reich-Stiebert et al., 2019).

Earliest forms of Lego first appeared in 1949 and took its final form in 1958. In 1955, in Nurnburg Toy Fair, System of Play was introduced and this was a turning point in the future of Lego. Pieces of bricks which later on led to Lego were patented in 1961 (Dönmez, 2007). In our time, Legos are programmable structures. Various software was developed to program these structures. Logo programming is one of these. Papert and his team developed the Logo software in 1960s in the Laboratories of Massachusetts Institute of Technology. (Resnick, 1993). After the emergence of software, a number of pieces have been added to Legos. They have become more functional with such pieces as engines, sensors and wheels. A number of new designs were seen thanks to Lego ${ }^{\circledR}$ Mindstorm NXT sets that appeared firstly in 1998 and were later developed in 2006. Lego ${ }^{\circledR}$ Mindstorm NXT series which offers richer options with its flexibility and various pieces is a preferred set in instructional processes especially in terms of its usability and applicability.

Lego ${ }^{\circledR}$ Mindstorms NXT robot kit, which was designed by the scientists of Massachusetts Institute of Technology, is a technology enabling students to develop robots on their own. In Lego ${ }^{\circledR}$ Mindstorms NXT sets, there are Lego bricks, an integrated system which enables controlling by computer, sensors (sound, light etc.) and engines for motion. Classical robot designing process requires high level of experience in such fields as mechanics, electronics and computer. However, mechanical structure of the robot designed by Lego bricks and programming of the robot with pre-integrated system and sensors can be performed at an easier level (Cavas et al., 2012).

By means of robots created by Legos, students can construct, program and design and they can also engage in entertaining, instructional, creative and collaborative activities. Robots created by Legos are efficient tools for students to learn several basic concepts of such fields as engineering and technology. Moreover, they make up instructional activities which help students develop their individual skills in the fields of engineering and technology. These robots develop students' mathematical thinking skills, collaborative learning skills, problem solving skills (Sáez-López, Sevillano-García \& Vazquez-Cano, 2019) and teach them scientific thinking, the logic behind programming and engineering processes (Sullivan, Bers \& Mihm, 2017).

Use of robots in education can be carried out either individually or by groups. The robot-student relation gains importance in terms of creative thinking in these processes. Students are expected to find creative solutions for the problems and to produce robotic products. Robot competitions can be quite efficient for students and student groups. As they are used in robotic instruction, they increase searching skills, willingness for exploring and group work skills (Şabanoviç \& Yannier, 2003). Use of robotic processes in education has been increasing day by day (Scherer et al., 2020). Researches reveal that robotic processes have positive effects in fields of Science, Mathematics, and Engineering (Benitti, 2012; Eguchi, 2010). It is possible to say that robotic practices increase work motivation as learners create indiviual learning environments and produce their own products (Lin et al., 2009; Lin, Liu \& Huang, 2012)

Kapa (1999) looked into effects of logo assisted learning environments on problem solving skills, group interaction and individual learning. 15 of the students were randomly grouped as pairs and 15 of them were grouped individually. There were meaningful differences between the logo group and other students in terms of problem solving. Logo support had positive effects in learning on both of the groups. Lindh and Holgersson (2007) carried out a research on $5^{\text {th }}$ grade students. In this research, effects of robotic toys (lego) on students' mathematic and problem-solving skills were searched. It was carried out in the form of pretest and posttest. Data from different age groups, classes and schools were gathered. As a result of the analysis, there was no meaningful difference between control group and experimental group, yet it was identified that students who enjoyed problem solving activities were more successful and also that ones who received lego-logo instruction were a lot more successful the following year.

Beisser (2006) emphasized the effect of lego-logo assisted instruction on female students' use of technology skills. According to the research, it was seen that female students couldn't make use of technology 
effectively and that they generally avoided using technology in problem solving processes. With computer assisted classes there was a rise in technology use of female students. They had more self-confidence after engaging in technology assisted classes. In the research carried out by Atmatzidou et al. (2008), primary and secondary school students' use of Lego ${ }^{\circledR}$ Mindstorms for programming subjects in learning environments was focused on. In the study, cooperation and competition of students were emphasized. With two problem sets, students were asked to identify robots' sensor using conditions. With this robotic study, students developed problem solving and programming skills and this increased the sense of competition in groups and thus they were prevented from losing their motivation.

McWorther (2008), in his study, aimed at identifying the learning and teaching connections between selfsetting learning and Lego ${ }^{\circledR}$ Mindstorms robotic activities in his computer programming course in the university. For this purpose, student motivation, learning strategies, and students' achieving the goals of the course were analyzed. No meaningful difference was found between the groups at the end of the study. The reason for this was seen inadequate number of lego pieces and robots. However, according to the survey, it was concluded that students had fun in lego practices and that by using lego, a number of learning tools or activities could be used in learning environments in many ways. Besides, it was understood that instruction with lego was an effective learning method in computer programming at university level.

In the master thesis written by Cayir (2010), whether lego-logo assisted learning environments had any effects on 8th grade students' scientific process skills and self-perception was analyzed. With the obtained data, it was concluded that lego-logo assisted learning environments had positive effects on students' selfperception. It was identified that in control and experimental groups, there was no meaningful difference in scientific process skills in the results of posttest scores and also it was determined that there was an increase in pre and post experimental processing skill levels of the students in the experimental group. It was revealed that lego-logo assisted learning processes had positive effects on self-perception and scientific process skills which are significant for the development of the students.

Sartori et al. (2012) studied the robotic learning processes of university students aged between 13 and 19 with Ingenium project for the purpose of developing curriculum. In the study, they identified that robotic environments improved the general school performance of the students. The study was carried out to identify the efficiency of learning through such learning approaches as peer learning, deductive learning, experiential learning, initiative learning and observational learning. How learning processes can more understandable or simplified was analyzed in order to improve instructional environments. At the end of the study, it was seen that robotic environments and peer learning had positive instructional effects on learners. Researchers suggested that learners should participate in the activities actively as they needed to increase their internal motivation.

In the study of Gandy et al. (2010), in order to test the basic level programming knowledge of the students who were studying in the departments of Computer, Engineering and Technology in Sunderland University, a project focusing on the use of Lego ${ }^{\circledR}$ Mindstorms NXT was designed. At the end of the project, it was seen that programming skills of the students had improved. On the other hand, in a study that was carried by Resinovic (2015) on a small group, it was seen that game programming and computer programming skills could be thought easily using humanoid robot and visual programming languages. Furthermore, it was emphasized that such practices would probably help students acquire robotic knowledge and skills and motivate them and improve their Computational Thinking skills.

In a research carried out by Saleiro et al. (2013), it is stated that by using low cost, classroom based, instructional robots, problem-based learning activities and mathematical reasoning education could be more successful and motivating. It is also indicated that these robot systems (PIC microcontroller, Arduino or Raspberry Pi based and programmed by Blockly), which do not require the installation of any additional software, can be used successfully even for $3^{\text {rd }}$ and $4^{\text {th }}$ grades. A Robot, developed by Yadagiri et al. (2015) to teach basic concepts of programming by robot programming, a labyrinth based instructional game and results of another study in which block based visual robot programming tool was used, showed that use of 
such learning environments in programming education for $12^{\text {th }}$ grades facilitated fast, simple and entertaining learning.

Depending on the results obtained from the literature; it can be asserted that robotics assisted programming and instructional robots are used commonly in classroom environments. Also, it can be stated that use of such tools helps students learn programming skills quickly, easily and entertainingly, increases their success and willingness and improve their motivation, creative thinking and problem-solving skills. In programming education, many concepts and processes remain abstract for students, and students have some difficulties in embodying the learned information. Concepts learned with traditional programming education are difficult and complex for students (Kunduracioğlu, 2018). With these difficulties, students cannot be motivated to programming lessons; depending on the decrease in motivation, problem solving skills decline and students' success decreases (Jenkins, 2001). It is thought that students' difficulties in understanding the concepts related to programming and their inability to structure them in their minds are due to the abstractness of the operations (Bosse \& Gerosa, 2016; Yukselturk \& Altiok, 2017). The problem status of this study is to provide robotic-assisted programming education with LEGO ${ }^{\circledR}$ Mindstorms training kits in order to increase motivation for the lesson, develop problem-solving skills and increase the success of the lesson. The aim of this research is to specify the effects of robotics assisted programming education on students' academic success, motivation and problem-solving skills.

\section{Methodology}

In this research, quasi-experimental design with pre-test and post-test control groups was used in order to identify the effects of robotics assisted programming language education on students' problem-solving skills, academic success and motivation levels. In this model, the groups were selected objectively as experimental and control groups. Experimental design are the ones that are used to explore the reason and result relation in the variables (Büyüköztürk, 2009). There are pre experimental and post experimental evaluation in both groups. The existence of pre-test in the model helps us to know pre-test similarity degrees of the groups and arrange the results of post-tests accordingly. Experimental design was performed only for the experimental group. In the beginning and final part of research evaluations were carried out in both groups using the same evaluation tools.

In the research, scores of the students receiving robotics assisted programming education and the scores of the ones who do not receive this kind of education, and whether there was a significant difference in students' problem-solving skills or not were analyzed. Of these student groups, students receiving robotics assisted programming education were separated as "experimental group" and; students receiving robotics unassisted programming education were separated as "control group". Besides, motivation levels of experimental and control groups were observed. In this part, post-test control group model was preferred in order to identify motivation levels of students.

\subsection{Participants}

The participants of the research are constituted by 50 university students who are studying in the Computer Education and Instructional Technologies department in College of Education of Gaziosmanpasa University and taking Programming Languages I course in the fall semester of 2016-2017 academic year. Participants were divided into two different groups so that 25 of the students were in the experimental group and 25 of them were in control group by doing objective assignment. Participants were assigned with equal probability and equal random selection by assigning them randomly in experimental and control groups. In the processing of the assignment, in terms of programming experience equal distribution of students according to kind of the high school from which they have graduated was focused on. Participants were also ranked according to success pre-test scores by forming equal pairs. Assignment in the groups were performed through objective assignment among from those equal pairs. The demographic characteristics of the participants are given Table 1. 
Table 1.

Demographics of the participants

\begin{tabular}{|c|c|c|c|c|c|c|}
\hline Groups & Group & Female & Male & $\begin{array}{l}\text { General } \\
\text { High } \\
\text { School }\end{array}$ & $\begin{array}{l}\text { Vocational } \\
\text { High School }\end{array}$ & $\begin{array}{l}\text { Classroom } \\
\text { Arrangement }\end{array}$ \\
\hline $\begin{array}{l}\text { Robotics Assisted Programming } \\
\text { Education Environment } \\
\text { (Experimental Group) }\end{array}$ & 25 & $\begin{array}{l}\% 52 \\
(f=13)\end{array}$ & $\begin{array}{l}\% 48 \\
(f=12)\end{array}$ & $\begin{array}{l}\% 64 \\
(f=16)\end{array}$ & $\begin{array}{l}\% 36 \\
(f=9)\end{array}$ & $\begin{array}{l}\text { Four teams of } 6 \\
\text { and } 7 \text { people }\end{array}$ \\
\hline $\begin{array}{l}\text { Robotics Unassisted Programming } \\
\text { Education Environment } \\
\text { (Experimental Group) }\end{array}$ & 25 & $\begin{array}{l}\% 56 \\
(\mathrm{f}=14)\end{array}$ & $\begin{array}{l}\% 44 \\
(f=11)\end{array}$ & $\begin{array}{l}\% 72 \\
(\mathrm{f}=18)\end{array}$ & $\begin{array}{l}\% 28 \\
(f=7)\end{array}$ & $\begin{array}{l}\text { Normal } \\
\text { Classroom } \\
\text { Arrangement }\end{array}$ \\
\hline
\end{tabular}

According to the demographic data in Table $1,52 \%(\mathrm{f}=13)$ of the participants in the experimental group $(\mathrm{f}=25)$ were female and $48 \%(\mathrm{f}=12)$ were male. Moreover, $64 \%(\mathrm{f}=16)$ of the students in the experimental group graduated from general high schools, and $36 \%(\mathrm{f}=9)$ of them graduated from a vocational high school. On the other hand, $56 \%(\mathrm{f}=14)$ of the participants in the control group $(\mathrm{f}=25)$ were female and $44 \%$ ( $f=11)$ were male. In addition, it is seen that $72 \%(f=18)$ of the students in the control group graduated from general high schools and $28 \%(f=7)$ graduated from a vocational high school. Therefore, experimental and control groups were formed in two groups of 25 each. Education in the control group was continued with normal classroom arrangement. In the experimental group, the students were divided into four groups consisting of 6 and 7 students and education was continued. The reason it is divided to groups is because there are four sets of LEGO ${ }^{\circledR}$ Mindstorms EV3 sets that will be used as robotics tools.

\subsection{Data Collecting Tools}

For the purpose of the study, the data were obtained by achievement test, problem solving inventory and motivation scale.

\subsubsection{Academic Achievement Test}

Academic achievement test was developed by the researcher to measure students' academic achievement. This achievement test is a test that includes multiple choice questions including Basic Programming Structures (Input, Output, Variable Declaration, Decision Making and Control, Function, Loop, Array).

In order to create an achievement test with multiple choice questions, a pool of items consisting of comprehension and application level questions was created. For the content and face validity of the test, a measurement and evaluation expert and four experts in the field of programming, computer education and instructional technology were consulted. In line with the experts' opinions, some of the questions were reorganized and options or questions were changed. The first draft form of the achievement test included 39 questions.

The reliability of the 39-question test form, which was prepared and finalized after the pilot application, was checked and it was applied to 79 students who took the Programming Languages I course and passed it successfully. Item discrimination ( $r$ ) and item difficulty indices ( $p$ ) were calculated for each item by item analysis after the application, and the values obtained are given. Test items with a low item difficulty indices and negative item discrimination indices were excluded from the test. As a result of the analysis, the discrimination indices of twelve question items was excluded from the test because it was below .20. Six items with item discrimination indices between .20 and .30 were rearranged in line with expert opinion. After the items with low discrimination indices were excluded from the test, the average discrimination index of the 20 -item test was found to be $r=.27$. 
When the difficulty indices of the items in the test is examined, the difficulty indices of the 39 items varies between .04 and .89 . The average difficulty indices was calculated as .50. According to results, it can be said that the test is a medium difficulty test. However, the KR20 internal consistency coefficients was calculated to measure the reliability of the test. The KR20 test is a reliability test that measures the internal consistency between the test scores obtained and is especially used in achievement tests. The KR20 reliability coefficient of the developed achievement test was calculated as .661. This coefficient shows that the test is a reliable measurement tool (Büyüköztürk, 2009).

\subsubsection{Instructional Materials Motivation Survey (IMMS)}

The Instructional Materials Motivation Survey (IMMS) developed by Keller (1993) and adapted into Turkish by Acar (2009) was used in order to measure the effect of robotics assisted programming education material used in the study on university students' motivation. The scale is a Likert type scale whose validity and reliability have been tested in many experimental studies (Keller, 1993; Gabrielle, 2003; Huett, 2006; Huang et al., 2004; Huang et al., 2006). The IMMS consists of 36 items. Students answered each item in the scale by scoring from 1 (Not Correct) to 5 (Very Correct). Accordingly, the lowest score on the scale is 36 , the highest score is 180 and the average score is 108 . Reliability coefficient of the IMMS was calculated as 0.96 .

\subsubsection{Problem Solving Inventory (PSI)}

In the study, Problem Solving Inventory (PSI) was used as a data collection tool to determine students' problem solving skills. The Problem Solving Inventory was developed by Heppner \& Peterson (1982) and adapted to Turkish by Şahin et al. (1993). PSI is a self-assessment measurement tool that measures an individual's perception of himself/ herself about problem solving skills. The scale is a Likert-type scale that is suitable for adolescents and adults, consists of 35 items and is scored between 1 and 6. Items 9, 22 and 29 are excluded in the process of scoring with respect to the measurement tool. The $1,2,3,4,11,13,14$, $15,17,21,25,26,30$ and 34. items in the scale are the reverse items. The score of the measurement tool is range between 32 and 192. The highest score that can be obtained from PSI is 192, and the lowest score is 32.

In the literature, there are informations about the reliability coefficients of the scale. Adaptation study to Turkish was done by Şahin et al. (1993) and its reliability was found to be .88. The Cronbach Alpha reliability coefficient is .93 according to Düzgün (2011), .74 according to Kardaş et al. (2014), .83 according to Kuloğlu \& Arı (2014), .79 according to Kaya (2019), and .76 according to Yıldız \& Beşoluk (2019).

\subsection{Data Collection and Practice Process}

This research is a 9-week-study, 8 weeks of which took place in the scope of Programming Languages I course in 2016-2017 academic year fall term and 1 week of which consisted the processes of data collection. Within the scope of the course what this research aim is teaching the logic of programming and structures related to programming. In the course content, there are basic concepts essential for grasping the logic of programming such as Input, Output, Variable Declaration, Decision Making and Control (Conditions), Function, Loop, Arrays.

The purpose behind the selection of Programming Languages I is that it is serves as an introduction course for programming education. In this study, analyzing the effect of robotics assisted programming education on learners' problem solving skills, academic success and motivation was aimed. In line with this purpose, Programming Languages I is an appropriate course in terms of course content, objective and process. Thus, main problems (Becker 2016; Denny et al., 2014; de Raadt 2008; Fisler et al., 2016; Ginat \& Scmalo, 2013; Muller, 2005; Robins et al., 2006; Sajaniemi \& Kuittinen 2005; Schulte \& Bennedsen, 2006) in teaching the logic of programming in the literature can be solved, and success, motivation and problem solving skills in the course of programming languages can be enhanced.

In the scope of the course, for the teaching of basic concepts, structures and logic of programming, we studied with 50 students who had registered in the course of Programming Languages I. Robotics assisted 
programming education group was chosen as the experimental group (EG) and the education was carried out with 25 students. In this group, ROBOTC activities with LEGO ${ }^{\circledR}$ Mindstorms EV3 education set were planned in order for the students to grasp the logic of programming structures. Robotics unassisted programming education group was chosen as the control group (CG) with 25 students. In this group, traditional programming education was carried out with $\mathrm{C}$ programming language.

Course contents were specified according to the course content guide of Computer Education and Instructional Technologies undergraduate program that takes place in teacher training programs in experimental and control groups. Content of the education in CG consisted of the activities which were carried out by Bloodshed Dev-C++ C programming language. EG consists of $\mathrm{LEGO}^{\circledR}$ Mindstorms EV3 activities carried out by ROBOTC programming language.

9 weeks of practice process was carried out including 8 weeks of lesson plans and 1 week of data collection. In the beginning and at the end of the practice process, Academic Achievement Test, PSI and IMMS were implemented to identify the effect of the practice on students' academic success, problem solving skills and motivation (Table 2).

Experimental practice process of the research lasted for 8 weeks within the scope of Programming Languages I course in 2016-2017 Academic Year Fall Term.

Table 2.

Research Practice Process

\begin{tabular}{|c|c|c|c|}
\hline Weeks & Groups & Practice Process, Topics & Data Collection Process \\
\hline \multicolumn{4}{|c|}{$\begin{array}{l}\text { 1. Information About the Practice Process } \\
\text { 2. Academic Achievement Pre-Test Practice } \\
\text { 3. Determination of Groups by Non-Random Assignment } \\
\text { • Experimental Group - } 25 \text { Students } \\
\text { • Control Group - 25 Students } \\
\end{array}$} \\
\hline \multirow[t]{2}{*}{ Week 1} & EG & $\begin{array}{l}\text { Introducing the LEGO }{ }^{\circledR} \text { Mindstorms } \\
\text { EV3 Set and the ROBOTC Application } \\
\text { and Programming }\end{array}$ & $\begin{array}{l}\text { Problem Solving Inventory Pre- } \\
\text { Test Practice }\end{array}$ \\
\hline & CG & $\begin{array}{l}\text { Introducing the Dev-C++ Application } \\
\text { and the } \mathrm{C} \text { Programming }\end{array}$ & $\begin{array}{l}\text { Problem Solving Inventory Pre- } \\
\text { Test Practice }\end{array}$ \\
\hline \multirow[b]{2}{*}{ Week 2} & EG & Motion and Advanced Motion & \\
\hline & $\mathrm{CG}$ & $\begin{array}{l}\text { Introduction to Input, Output and } \\
\text { Variables }\end{array}$ & \\
\hline \multirow[t]{2}{*}{ Week 3} & EG & $\begin{array}{l}\text { Detection with Loops (Touch and } \\
\text { Ultrasonic) }\end{array}$ & \\
\hline & CG & Loops & \\
\hline \multirow{2}{*}{ Week 4} & EG & Conditions (Movement Until Darkness) & \\
\hline & CG & Conditions (if-else) & \\
\hline \multirow{2}{*}{ Week 5} & EG & Conditions 2 (Line Following) & \\
\hline & CG & Conditions (Switch-Case) & \\
\hline \multirow{2}{*}{ Week 6} & EG & Variables & \\
\hline & $\mathrm{CG}$ & Variables & \\
\hline \multirow{2}{*}{ Week 7} & EG & Functions & \\
\hline & CG & Functions & \\
\hline \multirow{2}{*}{ Week 8} & EG & Remote Control (Arrays) & \\
\hline & CG & Arrays & \\
\hline
\end{tabular}




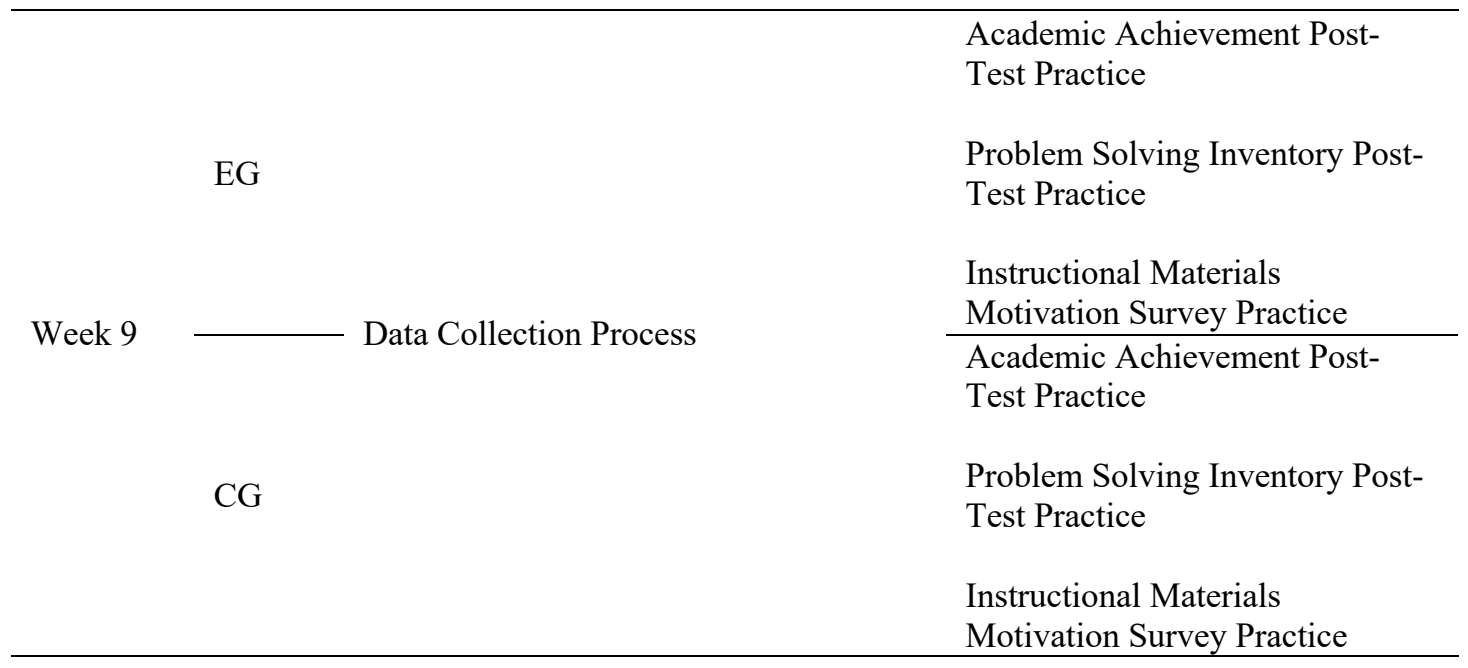

In regard to academic success preliminary test data and type of the high schools students had studied, EG and CG were identified. Hereunder, experimental process was initiated by assigning EG and CG 25 students each. In the first week, PSI was implemented in order to measure whether the students' problem solving skills in EG and CG changed or not at the beginning and end of the course. Besides, IMMS was implemented to measure the motivation of EG and CG at the end of 8-weeks process. It was aimed to identify students' academic achievement levels by repeating the Academic Achievement Test as posttest at the end of the course, which is implemented to identify EG and CG and to evaluate students' programming levels at the beginning of the course.

\subsection{Data Analysis}

SPSS 22.0 package program was used for the analysis of quantitative data. The normality assumptions of the measurement tools to be used to determine the problem solving skills, academic achievements and motivations of the students in the study were examined. The normality assumptions of the measurement tools to be used to determine the problem solving skills, academic achievements and motivations of the students in the study were examined. The Mann - Whitney U, Wilcoxon Signed Ranks Test, significance test of two mean differences (t-test) and Covariance Analysis (ANCOVA) statistical tests to be used in the analysis of the data was determined according to the conditions of meeting the normality assumptions.

\section{Findings}

\subsection{Findings Regarding Students' Problem Solving Skills in Experimental and Control Groups}

The findings related to the analysis of the data obtained from the Problem Solving Inventory in order to determine whether there is a statistically significant difference between the problem solving skills of the students in the experimental and control groups during the education process.

The results of the Mann-Whitney $U$ test conducted to determine the problem solving skills levels according to the pre-test scores of the experimental and control groups are given in Table 3.

Table 3.

Mann-Whitney U Test Results on Problem Solving Skills According to Pre-Test Scores of Experimental and Control Groups

\begin{tabular}{llcccccc}
\hline & Group & N & $\begin{array}{l}\text { Mean } \\
\text { Rank }\end{array}$ & $\begin{array}{l}\text { Rank } \\
\text { Sum }\end{array}$ & U & p & r \\
\hline \multirow{2}{*}{ Pre-test } & Experimental & 25 & 27,50 & 687,50 & & & \\
& & & & & 262,50 &, 332 &, 14 \\
& Control & 25 & 23,50 & 587,50 & & & \\
\hline
\end{tabular}


When Table 3 was examined, it was seen that there is no significant difference between the experimental and control groups in the problem solving skills of the students participating in the study $(U=262,50, p>, 05)$. It was seen that the effect size calculated as a result of the analysis was low level. $(r=, 14)$.

The results of the Mann-Whitney $U$ test conducted to determine the problem solving skills levels according to the post-test scores of the experimental and control groups are given in Table 4.

Table 4.

Mann-Whitney U Test Results on Problem Solving Skills According to Post-Test Scores of Experimental and Control Groups

\begin{tabular}{cccccccc}
\hline & Group & N & $\begin{array}{c}\text { Mean } \\
\text { Rank }\end{array}$ & $\begin{array}{c}\text { Rank } \\
\text { Sum }\end{array}$ & U & p & r \\
\hline \multirow{3}{*}{ Post-test } & Experimental & 25 & 29,76 & 744,00 & & & \\
& Control & 25 & 21,24 & 531,00 & 206,00 &, 039 &, 29 \\
& & & & & & & \\
\hline
\end{tabular}

When Table 4 was examined, it was found that there is a significant difference between the experimental and control groups in the level of problem solving skills related to the post-test scores $(U=206,00, p<, 05)$. Considering the mean ranks, it was understood that the students participating in robotics assisted programming education have higher problem solving skills than the students participating in the robotics unassisted programming education. This finding shows that robotics assisted programming education is effective in increasing students' problem solving skills. The effect size calculated as a result of the analysis showed that this significant difference was medium level $(r=, 29)$.

The results of the Wilcoxon Signed Ranks test conducted to determine the difference between the level of problem solving skills according to the pre-test and post-test scores of the experimental group are given in Table 5.

\section{Table 5.}

Wilcoxon Signed Ranks Test Results on Problem Solving Skills According to the Experimental Group Pre-test and Post-Test Scores

\begin{tabular}{lccccccc}
\hline & $\begin{array}{c}\text { Pre-test }- \text { Post- } \\
\text { test }\end{array}$ & N & $\begin{array}{c}\text { Mean } \\
\text { Rank }\end{array}$ & $\begin{array}{c}\text { Rank } \\
\text { Sum }\end{array}$ & Z & p & r \\
\hline $\begin{array}{l}\text { Experimental } \\
\text { Group }\end{array}$ & Negative Ranks & 6 & 12,25 & 73,50 & & & \\
& Positive Ranks & 18 & 12,58 & 226,50 & $2,19^{*}$ &, 029 &, 31 \\
& Equal & 1 & & & & & \\
& & & & & & & \\
\hline
\end{tabular}

* Based on Negative Ranks

When Table 5 was examined, it was determined that there is a significant difference between the preexperiment and post-experiment scores of the experimental group students participating in the study, which they got from the problem solving inventory depending on the studies $(Z=2,19, p<, 05)$. Considering the mean ranks and rank totals of the difference scores, it is seen that the observed difference is in favor of the positive ranks, that is, the posttest scores. According to the results, it can be said that robotics assisted programming education have an important contribution in improving students' problem solving skills. The effect size calculated as a result of the analysis showed that this significant difference was medium level ( $\mathrm{r}$ $=, 31$ ). 
The results of the Wilcoxon Signed Ranks test conducted to determine the difference between the level of problem solving skills according to the pre-test and post-test scores of the control group are given in Table 6.

Table 6.

Wilcoxon Signed Ranks Test Results on Problem Solving Skills According to the Control Group Pre-test and Post-Test Scores

\begin{tabular}{cccccccc}
\hline $\begin{array}{c}\text { Pre-test }- \\
\text { Post-test }\end{array}$ & N & $\begin{array}{c}\text { Mean } \\
\text { Rank }\end{array}$ & $\begin{array}{c}\text { Rank } \\
\text { Sum }\end{array}$ & Z & p & r \\
\hline & Negative Ranks & 9 & 15,28 & 137,50 & & & \\
Control Group & Positive Ranks & 16 & 11,72 & 187,50 &, $673^{*}$ &, 501 &, 10 \\
& Equal & 0 & & & & & \\
& & & & & & & \\
\hline
\end{tabular}

* Based on Negative Ranks

When Table 6 was examined, it was determined that there is no significant difference between the preexperiment and post-experiment scores of the control group students participating in the study from the problem-solving inventory depending on the studies $(Z=0,673, p>, 05)$. It was seen that the effect size calculated as a result of the analysis was low level $(\mathrm{r}=, 10)$.

\subsection{Findings Regarding Students' Achievement Levels in Experimental and Control Groups}

The findings related to the analysis of the data obtained from the Academic Achievement Test in order to determine whether there is a statistically significant difference between the academic achievement level of the students in the experimental and control groups during the education process.

The results of the t-test conducted to determine the academic achievement levels of the experimental group regarding the pre-test and post-test scores are given in Table 7.

Table 7.

t-test Results on Academic Achievement Levels According to Experimental Group's Pre-Test and Post-Test Scores

\begin{tabular}{ccccccccc}
\hline & & N & $\bar{x}$ & S & sd & t & p & r \\
\hline $\begin{array}{c}\text { Experimental } \\
\text { Group }\end{array}$ & Pre-test & 25 & 41,04 & 12,44 & & & & \\
& Post-test & 25 & 62,88 & 14,50 & & & & \\
& & & & & & & &
\end{tabular}

When Table 7 was examined, it was seen that there is a significant difference in the academic achievement levels of the experimental group students participating in the study regarding the pre-test and post-test scores $(t=-5,129, p<, 05)$. It was determined that the academic achievement levels of the experimental group students according to their post-test scores $(\bar{x}=62,88)$ were significantly higher than their academic achievement levels based on their pre-test scores $(\bar{x}=41,04)$. This finding shows that there is a significant increase in students' learning during the course. The effect size calculated as a result of the analysis showed that this significant difference was at a high level $(r=, 60)$.

The results of the t-test conducted to determine the academic achievement levels of the control group regarding the pre-test and post-test scores are given in Table 8. 


\section{Table 8.}

t-test Results on Academic Achievement Levels According to Control Group's Pre-Test and Post-Test Scores

\begin{tabular}{ccccccccc}
\hline & & N & $\bar{x}$ & S & sd & t & p & r \\
\hline \multirow{3}{*}{ Control Group } & Pre-test & 25 & 41,28 & 10,40 & & & & \\
& & & & & 48 & $-5,687$ &, 000 &, 63
\end{tabular}

When Table 8 was examined, it was seen that there is a significant difference in the academic achievement levels of the control group students participating in the study regarding the pre-test and post-test scores $(\mathrm{t}=$ $-5,687, \mathrm{p}<, 05)$. It was determined that the academic achievement levels of the control group students according to their post-test scores $(\bar{x}=59,12)$ were significantly higher than their academic achievement levels based on their pre-test scores $(\bar{x}=41,28)$. This finding shows that there is a significant increase in students' learning during the course. The effect size calculated as a result of the analysis showed that this significant difference was at a high level $(\mathrm{r}=, 63)$.

In order to determine the academic achievement levels of the experimental and control groups according to the pretest scores, the significance test (t-test) values of the two mean differences are given in Table 9.

Table 9.

t-test Results Related to Academic Achievement Levels of Experimental and Control Groups According to Pre-Test Scores

\begin{tabular}{ccccccccc}
\hline & Group & N & $\bar{x}$ & S & sd & t & p & r \\
\hline \multirow{3}{*}{ Pre-test } & Experimental & 25 & 41,04 & 12,44 & & & & \\
& Control & 25 & 41,28 & 10,40 & & & & \\
& & & & & & & &
\end{tabular}

When Table 9 was examined, it was seen that there is no significant difference between the experimental and control groups in the academic achievement levels of the students participating in the study $(\mathrm{t}=-0,049$, $\mathrm{p}>, 05)$. According to the pre-test, the academic achievement levels of robotics assisted programming education students participating in the study were found to be $\bar{x}=41,04$, and the academic achievement levels of robotics unassisted programming education students to be $\bar{x}=41,28$. It was seen that the effect size calculated as a result of the analysis was low $(r=, 01)$.

In order to examine the effect of experimental and control group's post-test academic achievement, covariance analysis (ANCOVA) was performed by controlling the pre-test scores of the students. As a result of the analysis, the post-test mean scores adjusted according to the pre-test scores of the experimental and control groups are given in Table 10.

Table 10.

Descriptive Statistics of Post-Test Scores of Experimental and Control Groups

\begin{tabular}{cccc}
\hline Groups & N & Mean & Adjusted Mean \\
\hline Experimental Group & 25 & 62,88 & 62,93 \\
Control Group & 25 & 59,12 & 59,07 \\
\hline
\end{tabular}

According to the adjusted post-test scores, it was observed that the mean score of the experimental group increased and the mean score of the control group decreased. The results of the covariance analysis 
(ANCOVA) performed to test the significance of the difference between the adjusted academic achievement post-test scores of the groups are given in Table 11.

Table 11.

ANCOVA Results of Post-Test Scores According to Academic Achievement Levels

\begin{tabular}{ccccccc}
\hline Source of Variance & Sum of Squares & sd & Mean of Squares & F & Significance Level (p) & $\boldsymbol{\eta}_{\mathbf{p} 2}$ \\
\hline Pre-test score (reg.) & 443,264 & 1 & 443,264 & 9,80 &, 003 &, 173 \\
Group & 185,802 & 1 & 185,802 & 4,11 &, 048 &, 080 \\
Error & 2126,016 & 47 & 45,234 & & & \\
Total & 2746,000 & 49 & & & & \\
\end{tabular}

When Table 11. was examined, according to the results of the analysis of covariance, a significant difference was observed between the post-test scores adjusted according to the pre-test scores of the experimental and control groups $\left(\mathrm{F}(1-47)=4,11, \mathrm{p}=, 048, \eta_{\mathrm{p}} 2=, 080\right)$. The adjusted post-test scores of the control group $(\bar{x}=59,07)$ are significantly lower than the adjusted post-test scores of the experimental group $(\bar{x}=62,93)$. As a result of the analysis, the effect size $\left(\eta_{\mathrm{p}} 2\right)$ value was found, 080 . The effect size calculated as a result of the analysis showed that this significant difference was medium level $\left(, 06>\eta_{\mathrm{p}}{ }^{2}\right.$ $>, 14)$.

\subsection{Findings Regarding the Motivation Levels of the Experimental and Control Groups}

The findings related to the analysis of the data obtained from the IMMS in order to determine whether there is a statistically significant difference between the motivation levels of the students in the experimental and control groups regarding the educational process.

In order to determine the motivation levels of the experimental and control groups, the significance test values of the two mean differences (t-test) are given in Table 12.

Table 12.

t-test Results Related to the Motivation Levels of the Experimental and Control Groups

\begin{tabular}{lcccccccc}
\hline & Group & N & $\bar{x}$ & S & sd & t & p & r \\
\hline \multirow{3}{*}{ Motivation } & Experimental & 25 & 3,35 &, 41 & & & & \\
& Control & 25 & 3,14 &, 32 & 48 & 2,070 &, 044 &, 29
\end{tabular}

When Table 12 was examined, it was seen that there is a significant difference between the experimental and control groups regarding the motivation levels of the students participating in the study $(\mathrm{t}=2,070$, $\mathrm{p}<, 05)$. It was found that the motivation levels of robotics assisted programming education students $(\bar{x}$ $=3,35$ ) participating in the study were significantly higher than the motivation levels of robotics unassisted programming education students $(\bar{x}=3,14)$. Accordingly, it was seen that students who receive robotics assisted programming education are more motivated to course of Programming Languages I than students who receive robotics unassisted programming education. The effect size calculated as a result of the analysis showed that this significant difference was medium level $(\mathrm{r}=, 29)$. 


\section{Conclusion and Suggestions}

Within the scope of the research, it was aimed to examine the effect of robotics assisted programming education on students' problem solving skills, academic achievement and motivation towards the lesson. According to the results obtained in line with this purpose, it was found that there was no significant difference between the experimental and control groups before the study, but this situation changed after the study. After the experimental process, a significant difference was found between the experimental and control groups. With this significant difference, which has a medium level effect, the problem solving skills of the robotics assisted programming education group are higher than the robotics unassisted programming education group. According to this result, it was believed that robotics assisted programming education with LEGO ${ }^{\circledR}$ Mindstorms is a more effective and efficient tool for improving students' problem solving skills compared to traditional programming education. Another finding supporting this result is that the experimental group had a significant difference between pre-experiment and post-experiment problemsolving skills. The calculated effect size showed that this significant difference was medium level. It was found that problem solving skills of the experimental group students who received robotics assisted programming with LEGO ${ }^{\circledR}$ Mindstorms increased after the experiment compared to the pre-experiment. However, there was no difference between control group students' problem solving skills before and after the experiment. This result supports again that robotics assisted programming education with LEGO $^{\circledR}$ Mindstorms is a process that develops students' problem-solving skills. As a result of the obtained data, it was seen that the robotics assisted education process with LEGO ${ }^{\circledR}$ Mindstorms increases students' problem solving skills. This result shows similarities to other research results in the literature (Alimisis \& Kynigos, 2009; Atmatzidou et al., 2008; Atmatzidou et al., 2018; Avcı \& Şahin, 2019; Castledine \& Chalmers, 2011; Chaudhary et al., 2016; Nourbakhsh et al, 2005; Cavas et al., 2012; Danahy et al., 2013; Lin et al., 2009; Mioduser et al., 2009). Barak \& Zadok (2009) found that students participating in robotics activities frequently used heuristic findings in the classroom (the processes in which problem solvers determine their solution methods) based on their own life experiences. The heuristics used by students can be activated to strengthen and extend students' real-life problem solving abilities.

It was observed that there was a significant difference in the academic achievement levels of the experimental group students participating in the study regarding the pre-study and post-study scores. The effect size calculated as a result of the analysis showed that this significant difference was high level. This result showed that robotics assisted programming education with LEGO ${ }^{\circledR}$ Mindstorms increased the academic success of students. In addition, it was determined that there was a significant difference in the academic achievement levels of the control group students participating in the study regarding their pre and post scores. The effect size calculated as a result of the analysis showed that this significant difference was high level. This result shows that there is a significant increase in students' learning during the traditional lesson. It was found that there was no significant difference between the academic achievement levels between the experimental and control groups before the study, but there was a significant difference between the post-test scores of the experimental and control groups after the study. The effect size calculated as a result of the analysis showed that this significant difference was medium level. According to this result, the academic success scores of the robotics assisted programming education group were significantly higher than the academic achievement scores of the robotics unassisted programming education group. With this result, it is believed that robotics assisted programming education is an effective and successful method for learning programming. This result shows similarities to the Barker \& Ansorge (2007), Çukurbaş1 (2016), Garcia \& Patterson-McNeill (2002), Korkmaz (2016), Lawhead et all., (2002), Özdoğru (2013) and Strawhacker \& Bers (2015) research results in the literature.

According to the study, it was found that there was a significant difference between the experimental and control groups regarding the motivation levels of the participants. The motivation levels of robotics assisted programming education students participating in the study were found to be significantly higher than the robotics unassisted programming education students. The effect size calculated as a result of the analysis showed that this significant difference was at a medium level. This result can be interpreted as that students 
who receive robotics assisted programming education are more motivated to course of Program Languages I than students who receive robotics unassisted programming education. This result shows similarities research results of Çukurbaşı \& Kıyıcı (2017), Lykke et all., (2014), McWhorter \& O'Connor (2009), Nugent et all., (2009) and Piteira \& Haddad (2011) in the literature. Martínez Ortiz (2015) was found that LEGO $^{\circledR}$ Mindstorms practices increase students' motivation to learn. Buckler (2015) stated that, according to his research, student motivation is among the in-class factors that contribute to student success. In this study, it was believe that as students are motivated for the lesson and there is increase in their motivation levels, robotics assisted programming education process with lego mindstorms increases their academic achievement.

According to this research, the use of robotic tools in programming education increases motivation, success and problem-solving skills. For this reason, it is recommended that students should be given programming education using robotics tools instead of traditional programming education. In order to develop students' cognitive high-level skills and psychomotor skills, it is recommended that programming education be taught with robotic tools from the primary education level and robotics assisted programming education should be added to the curriculum of relevant educational institutions.

\section{References}

Acar, S. (2009). The effects of ARCS motivation strategies on learners academic succeses, permanances of learning, motivations and attitudes in web supported performance based learning (Publication No. 234402). [Doctoral dissertation, Gazi University].YÖK Thesis Center Database.

Alimisis, D., \& Kynigos, C. (2009). Constructionism and robotics in education. Teacher education on robotic-enhanced constructivist pedagogical methods, 11-26. http://roboesl.eu/wpcontent/uploads/2017/08/chapter_1.pdf

Atmatzidou, S., Demetriadis, S., \& Nika, P. (2018). How Does the Degree of Guidance Support Students' Metacognitive and Problem Solving Skills in Educational Robotics?. Journal of Science Education and Technology, 27(1), 70-85. https://doi.org/10.1007/s10956-017-9709-x

Atmatzidou, S., Markelis, I., \& Demetriadis, S. (2008). The use of LEGO Mindstorms in elementary and secondary education: game as a way of triggering learning. In International Conference of Simulation, Modeling and Programming for Autonomous Robots (SIMPAR). Venice, Italy. http://www.dei.unipd.it/ emg/downloads/SIMPAR08WorkshopProceedings/TeachingWithRoboti cs/atmatzidou et al.pdf

Avc1, B., \& Şahin, F. (2019). The effect of LEGO Mindstorm projects on problem solving skills and scientific creativity of teacher. Journal of Human Sciences, 16(1), 216-230. https://doi.org/10.14687/jhs.v16i1.5658

Barak, M., \& Zadok, Y. (2009). Robotics projects and learning concepts in science, technology and problem solving. International Journal of Technology and Design Education, 19(3), 289-307. https://doi.org/10.1007/s10798-007-9043-3

Barker, B. S., \& Ansorge, J. (2007). Robotics as means to increase achievement scores in an informal learning environment. Journal of research on technology in education, 39(3), 229-243. https://doi.org/10.1080/15391523.2007.10782481

Becker, B. A. (2016). An effective approach to enhancing compiler error messages. In Proceedings of the 47th ACM Technical Symposium on Computing Science Education(ss. 126-131). ACM. https://doi.org/10.1145/2839509.2844584

Beisser, S. R. (2005). An examination of gender differences in elementary constructionist classrooms using Lego/Logo instruction. Computers in the Schools, 22(3-4), 7-19. https://www.tandfonline.com/doi/abs/10.1300/J025v22n03 02

Benitti, F. B. V. (2012). Exploring the educational potential of robotics in schools: A systematic review. Computers \& Education, 58(3), 978-988. https://doi.org/10.1016/j.compedu.2011.10.006 
Bosse, Y., \& Gerosa, M. A. (2017). Why is programming so difficult to learn? Patterns of Difficulties Related to Programming Learning Mid-Stage. ACM SIGSOFT Software Engineering Notes, 41(6), 1-6. https://doi.org/10.1145/3011286.3011301

Buckler, A. (2015). An exploratory study of student and teacher perceptions on student motivation and the teacher-student relationship (Publication No. 3708723) [Doctoral dissertation, Regent University]. ProQuest Dissertations and Theses Global.

Büyüköztürk, Ş. (2009). Sosyal bilimler için veri analizi el kitabı (10. Ed.). Ankara: Pegem Akademi.

Castledine, A. R., \& Chalmers, C. (2011). LEGO Robotics: An authentic problem solving tool?. Design and Technology Education: An International Journal, 16(3). https://ojs.lboro.ac.uk/DATE/article/view/1661

Cavas, B., Kesercioglu, T., Holbrook, J., Rannikmae, M., Ozdogru, E., \& Gokler, F. (2012). The effects of robotics club on the students' performance on science process \& scientific creativity skills and perceptions on robots, human and society. In Proceedings of 3rd International Workshop Teaching Robotics, Teaching with Robotics Integrating Robotics in School Curriculum (ss. 40-50). http://www.terecop.eu/TRTWR2012/trtwr2012 submission_06.pdf

Cayir, E. (2010). Assignment the effect of learning environment supported by lego-logo on science process skill and self concept (Publication No. 265835). [Master's Thesis, Sakarya University].YÖK Thesis Center Database.

Chaudhary, V., Agrawal, V., Sureka, P., \& Sureka, A. (2016). An experience report on teaching programming and computational thinking to elementary level children using LEGO robotics education kit. In 2016 IEEE Eighth International Conference on Technology for Education (T4E) (ss. 38-41). IEEE. https://doi.org/10.1109/T4E.2016.016

Çukurbaş1, B. (2016). Examine the effect of the problem based learning activities supported via flipped classroom and lego-logo practices on the high school students' success and their motivation (Publication No. 448207). [Doctoral dissertation, Sakarya University].YÖK Thesis Center Database.

Çukurbaşı, B., \& Kıyıc1, M. (2017). An Investigation of the Effects of Problem-Based Learning Activities Supported via Flipped Classroom and LEGO®-LOGO Practices on the Success and Motivation of High School Students. International Online Journal of Educational Sciences,9(1). http://dx.doi.org/10.15345/iojes.2017.01.013

Danahy, E., Wang, E., Brockman, J., Carberry, A., Shapiro, B. \& Rogers, C. B. (2013). LEGO®-based Robotics in Higher Education: 15 Years of Student Creativity. International Journal of Advanced Robotic Systems, 11, 1-15. https://doi.org/10.5772/58249

de Raadt, M. (2008). Teaching programming strategies explicitly to novice programmers [Doctoral dissertation, University of Southern Queensland]. https://core.ac.uk/download/pdf/11038092.pdf

Denny, P., Luxton-Reilly, A., \& Carpenter, D. (2014). Enhancing syntax error messages appears ineffectual. In Proceedings of the 2014 conference on Innovation \& technology in computer science education (ss. 273-278). ACM. https://doi.org/10.1145/2591708.2591748

Dönmez, F. (2007). Determining the science process skill levels of technical high school students (Publication No. 177990). [Master's Thesis, Balıkesir University].YÖK Thesis Center Database.

Düzgün, Z. (2011). The relationship between the problem solving skills and the thinking styles of science and technology teachers use (Publication No. 298640). [Master's Thesis, Marmara University].YÖK Thesis Center Database.

Eguchi, A. (2014). Educational Robotics Theories and Practice: Tips for how to do it Right. In Robotics: Concepts, Methodologies, Tools, and Applications (pp. 193-223). IGI Global. https://doi.org/10.4018/978-1-4666-0182-6.CH001

Fisler, K., Krishnamurthi, S., \& Siegmund, J. (2016). Modernizing plan-composition studies. In Proceedings of the 47th ACM Technical Symposium on Computing Science Education (ss. 211216). ACM. https://doi.org/10.1145/2839509.2844556 
Gabrielle, D. (2003). The effects of technology-mediated instructional strategies on motivation, performance, and self-directed learning. In EdMedia+ Innovate Learning (ss. 2568-2575). Association for the Advancement of Computing in Education (AACE). http:/gabrielleconsulting.com/docs/gabrielleaect.pdf

Gandy, E. A., Bradley, S., Arnold-Brookes, D., \& Allen, N. R. (2010). The use of lego mindstorms nxt robots in the teaching of introductory java programming to undergraduate students. Innovation in Teaching and Learning in Information and Computer Sciences,9(1), 2-9. https://doi.org/10.11120/ital.2010.09010002

Garcia, M. A., \& Patterson-McNeill, H. (2002). Learn how to develop software using the toy LEGO Mindstorms. In 32nd Annual Frontiers in Education (Vol. 3, pp. S4D-S4D). IEEE. https://doi.org/10.1109/FIE.2002.1158730

Ginat, D., \& Shmalo, R. (2013). Constructive use of errors in teaching CS1. In Proceeding of the 44th ACM technical symposium on Computer science education(ss. 353-358). ACM. https://doi.org/10.1145/2445196.2445300

Heppner, P. P., \& Petersen, C. H. (1982). The development and implications of a personal problem-solving inventory. Journal of counseling psychology, 29(1), 66. https://doi.org/10.1037/0022-0167.29.1.66

Heppner, P.P. (1988). Problem Solving Inventory (PSI): Research Manual. Palo Alto, CA: Consulting Psychologists

Press. https://www.researchgate.net/profile/Puncky_Heppner/publication/232588800_Applications_of_t he Problem Solving Inventory/links/57732ae108ae2b93e1a7d2d3.pdf

Huang, D. W., Diefes-Dux, H., Imbrie, P. K., Daku, B., \& Kallimani, J. G. (2004). Learning motivation evaluation for a computer-based instructional tutorial using ARCS model of motivational design. In 34th Annual Frontiers in Education, 2004. FIE 2004. (ss. T1E-30). IEEE. https://doi.org/10.1109/FIE.2004.1408466

Huang, W., Huang, W., Diefes-Dux, H., \& Imbrie, P. K. (2006). A preliminary validation of Attention, Relevance, Confidence and Satisfaction model-based Instructional Material Motivational Survey in a computer-based tutorial setting. British Journal of Educational Technology, 37(2), 243-259. https://doi.org/10.1111/j.1467-8535.2005.00582.x

Huett, J. B. (2006). The effects of ARCS-based confidence strategies on learner confidence and performance in distance education. University of North Texas. https://digital.library.unt.edu/ark:/67531/metadc5268/m1/2/

Jenkins, T. (2001, June). The motivation of students of programming. In Proceedings of the 6th annual conference on Innovation and technology in computer science education (pp. 53-56). https://doi.org/10.1145/377435.377472

Kardaş, N., Anagün, Ş. S., \& Yalçınoğlu, P. (2014). Adaptation of Problem Solving Inventory for the Elemantart School Students: Confirmatory Factor Analysis. Electronic Journal of Social Sciences, 13(51), 182-194. https://doi.org/10.17755/esosder.35695

Kaya, S. (2019). Investigation of the relationship between resilience and problem solving skill levels of elite basketball players fighting in different leagues (Publication No. 544287). [Master's Thesis, Balıkesir University].YÖK Thesis Center Database.

Keller, J. M. (1993). Manual for the instructional materials motivational survey (IMMS). Unpublished manuscript, Florida State University, Tallahassee, FL.

Keller, J. M. (2006). Development of two measures of learner motivation. Unpublished manuscript in progress. Florida State University, Tallahassee, FL.

Korkmaz, O. (2016). The effect of LEGO Mindstorms Ev3 based design activities on students' attitudes towards learning computer programming, self-efficacy beliefs and levels of academic achievement. Baltic Journal of Modern Computing, 4(4), 994-1007. http://doi.org/10.22364/bjmc.2016.4.4.24

Kuloğlu, A., \& Arı, Ü. (2014). Examinatıon of science and technology teacher candidates' problem solving skills in terms of some variables. Kilis 7 Aralık University Journal of Social Sciences, 4(8), 94-109. https://dergipark.org.tr/tr/download/article-file/717405 
Kunduracioğlu, İ. (2018). Examining the interface of lego mindstorms ev3 robot programming. Journal of Educational Technology and Online Learning, 1(1), 28-46.

https://doi.org/10.31681/jetol.372826

Lawhead, P. B., Duncan, M. E., Bland, C. G., Goldweber, M., Schep, M., Barnes, D. J., \& Hollingsworth, R. G. (2002). A road map for teaching introductory programming using LEGOC) mindstorms robots. In Acm sigcse bulletin (Vol. 35, No. 2, pp. 191-201). ACM. https://doi.org/10.1145/960568.783002

Lin, C. H., Liu, E. Z. F., \& Huang, Y. Y. (2012). Exploring parents' perceptions towards educational robots: Gender and socio-economic differences. British Journal of Educational Technology, 43(1), E31E34. https://doi.org/10.1111/j.1467-8535.2011.01258.x

Lin, C. H., Liu, E. Z. F., Kou, C. H., Virnes, M., Sutinen, E., \& Cheng, S. S. (2009). A case analysis of creative spiral instruction model and students' creative problem solving performance in a LEGO® robotics course. In International Conference on Technologies for E-Learning and Digital Entertainment (ss. 501-505). Springer, Berlin, Heidelberg. https://doi.org/10.1007/978-3-64203364-3 61

Lindh, J., \& Holgersson, T. (2007). Does lego training stimulate pupils' ability to solve logical problems?. Computers \& education, 49(4), 1097-1111. https://doi.org/10.1016/j.compedu.2005.12.008

Lykke, M., Coto, M., Mora, S., Vandel, N., \& Jantzen, C. (2014). Motivating programming students by problem based learning and LEGO robots. In 2014 IEEE Global Engineering Education Conference (EDUCON) (pp. 544-555). IEEE. https://doi.org/10.1109/EDUCON.2014.6826146

Martínez Ortiz, A. (2015). Examining Students' Proportional Reasoning Strategy Levels as Evidence of the Impact of an Integrated LEGO Robotics and Mathematics Learning Experience. Journal of Technology Education, 26(2), 46-69. http://scholar.lib.vt.edu/ejournals/JTE/v26n2/pdf/martinez.pdf

McWhorter, W. I. (2008). The effectiveness of using LEGO ${ }^{\circledR}$ Mindstorms ${ }^{\circledR}$ robotics activities to influence self-regulated learning in a university introductory computer programming course [Doctoral dissertation, University of North Texas]. https://digital.library.unt.edu/ark:/67531/metadc6077/

McWhorter, W. I., \& O'Connor, B. C. (2009). Do LEGO ${ }^{\circledR}$ Mindstorms ${ }^{\circledR}$ motivate students in CS1?. In ACM SIGCSE Bulletin (Vol. 41, No. 1, pp. 438-442). ACM. https://doi.org/10.1145/1508865.1509019

Mioduser, D., Levy, S. T., \& Talis, V. (2009). Episodes to scripts to rules: Concrete-abstractions in kindergarten children's explanations of a robot's behavior. International Journal of Technology and Design Education, 19(1), 15-36. https://doi.org/10.1007/s10798-007-9040-6

Muller, O. (2005). Pattern oriented instruction and the enhancement of analogical reasoning. In Proceedings of the first international workshop on Computing education research (ss. 57-67). ACM. https://doi.org/10.1145/1089786.1089792

Nourbakhsh, I. R., Crowley, K., Bhave, A., Hamner, E., Hsiu, T., Perez-Bergquist, A., Richards, S. \& Wilkinson, K. (2005). The robotic autonomy mobile robotics course: Robot design, curriculum design and educational assessment. Autonomous Robots, 18(1), 103-127. https://doi.org/10.1023/B:AURO.0000047303.20624.02

Nugent, G., Barker, B., Grandgenett, N., ve Adamchuk, V. (2009). The use of digital manipulatives in k12: robotics, GPS/GIS and programming. In 2009 39th IEEE Frontiers in Education Conference (ss. 1-6). IEEE. https://doi.org/10.1109/FIE.2009.5350828

Özdoğru, E. (2013). The effect of Lego programme based science and technology education on the students academic achievement, science process skills and their attitudes toward Science and Technology course for pyhsical facts learning field (Publication No. 342333). [Master's Thesis, Dokuz Eylül University].YÖK Thesis Center Database.

Piteira, M., \& Haddad, S. R. (2011). Innovate in your program computer class: an approach based on a serious game. In Proceedings of the 2011 Workshop on Open Source and Design of Communication (pp. 49-54). ACM. https://doi.org/10.1145/2016716.2016730 
Reich-Stiebert, N., Eyssel, F., \& Hohnemann, C. (2019). Involve the user! Changing attitudes toward robots by user participation in a robot prototyping process. Computers in Human Behavior, 91, 290-296. https://doi.org/10.1016/j.chb.2018.09.041

Resinovic, B. (2015). The use of Nao, a humanoid robot, in teaching computer programming. In The Proceedings of International Conference on Informatics in Schools: Situation, Evolution and Perspectives-ISSEP (p. 63). http://issep15.fri.uni-lj.si/files/issep2015-proceedings.pdf

Resnick, M. (1993). Behavior construction kits. Communications of the ACM, 36(7), 64-71. https://doi.org/10.1145/159544.159593

Resnick, M., Martin, F., Sargent, R., \& Silverman, B. (1996). Programmable bricks: Toys to think with. IBM Systems journal, 35(3.4), 443-452. https://doi.org/10.1147/sj.353.0443

Robins, A., Haden, P., \& Garner, S. (2006). Problem distributions in a CS1 course. In Proceedings of the 8th Australasian Conference on Computing Education-Volume 52(ss. 165-173). Australian Computer Society, Inc.. https://dl.acm.org/doi/pdf/10.5555/1151869.1151891

Sáez-López, J. M., Sevillano-García, M. L., \& Vazquez-Cano, E. (2019). The effect of programming on primary school students' mathematical and scientific understanding: educational use of mBot. Educational Technology Research and Development, 67(6), 1405-1425. https://doi.org/10.1007/s11423-019-09648-5

Sajaniemi, J., \& Kuittinen, M. (2005). An experiment on using roles of variables in teaching introductory programming. Computer Science Education, 15(1), 59-82. https://doi.org/10.1080/08993400500056563

Saleiro, M., Carmo, B., Rodrigues, J. M., \& du Buf, J. H. (2013). A low-cost classroom-oriented educational robotics system. In International Conference on social robotics (pp. 74-83). Springer, Cham. https://doi.org/10.1007/978-3-319-02675-6 8

Sartori, T., Burlin, L., Casonato, G., Costantini, M., Cozzarolo, A. Marcato, O., Matteazzi, M., Scardanzan, C., Vecchia, S., Vettor, V. \& Zamperini, A. (2012). Ingenium: an exploratory research on learning processes specific to robotic labs. In Proceedings of 3rd International Workshop Teaching Robotics, Teaching with Robotics Integrating Robotics in School Curriculum Riva del Garda. Trento, Italy. http://www.terecop.eu/TRTWR2012/trtwr2012_submission_12.pdf

Scherer, R., Siddiq, F., \& Viveros, B. S. (2020). A meta-analysis of teaching and learning computer programming: Effective instructional approaches and conditions. Computers in Human Behavior, 106349. https://doi.org/10.1016/j.chb.2020.106349

Schulte, C., \& Bennedsen, J. (2006). What do teachers teach in introductory programming?. In Proceedings of the second international workshop on Computing education research (ss. 17-28). ACM. https://doi.org/10.1145/1151588.1151593

Strawhacker, A., \& Bers, M. U. (2015). "I want my robot to look for food": Comparing Kindergartner's programming comprehension using tangible, graphic, and hybrid user interfaces. International Journal of Technology and Design Education, 25(3), 293-319. https://doi.org/10.1007/s10798-0149287-7

Sullivan, A. A., Bers, M. U., \& Mihm, C. (2017). Imagining, playing, and coding with KIBO: using robotics to foster computational thinking in young children. Siu-cheung KONG The Education University of Hong Kong, Hong Kong, 110. https://ase.tufts.edu/devtech/publications/Sullivan_Bers_Mihm_KIBOHongKong\%20.pdf

Şabanoviç, A., \& Yannier, S. (2003). Robotlar: Sosyal etkileşimli makineler. TÜBİTAK Bilim Teknik Dergisi. https://www.academia.edu/download/42760973/sosyaletki.pdf

Şahin, N., Şahin, N. H., ve Heppner, P. P. (1993). The psychometric properties of the Problem Solving Inventory. Cognitive Therapy and Research, 17, 4, 379-396. https://doi.org/10.1007/BF01177661 
Whitebread, D., Neale, D., Jensen, H., Liu, C., Solis, S. L., Hopkins, E., ... \& Zosh, J. (2017). The role of play in children's development: a review of the evidence. LEGO Fonden.

https://cms.learningthroughplay.com/media/esriqz2x/role-of-play-in-childrens-developmentreview_web.pdf

Yadagiri, R. G., Krishnamoorthy, S. P., \& Kapila, V. (2015, June). A blocks-based visual environment to teach robot-programming to K-12 students. In 2015 ASEE Annual Conference \& Exposition (pp. 26-17). https://doi.org/10.18260/p.23358

Yıldız, Ş., \& Beşoluk, Ş. (2019). The Investigation of the Effect of Problem Based Teaching Approach on Students' Problem Solving Skills and Academic Achievements in Science Course. Journal of Individual Differences in Education, 1(1), 50-68. https://dergipark.org.tr/tr/pub/jide/issue/45463/569081

Yukselturk, E., \& Altiok, S. (2017). An investigation of the effects of programming with Scratch on the preservice IT teachers' self-efficacy perceptions and attitudes towards computer programming. British Journal of Educational Technology, 48(3), 789-801. https://doi.org/10.1111/bjet.12453 